\title{
Association of vitamin D with adiposity measures and other determinants in a cross-sectional study of Cypriot adolescents
}

\author{
Ourania Kolokotroni ${ }^{1,2,3, *}$, Anna Papadopoulou ${ }^{4}$, Panayiotis K Yiallouros ${ }^{1}$, \\ Vasilios Raftopoulos ${ }^{2}$, Christiana Kouta ${ }^{2}$, Demetris Lamnisos ${ }^{1,2}$, Polyxeni Nicolaidou ${ }^{4}$ \\ and Nicos Middleton ${ }^{2}$ \\ ${ }^{1}$ Cyprus International Institute for Environmental \& Public Health in association with Harvard School of Public \\ Health, Cyprus University of Technology, 95 Irenes Street, 3041 Limassol, Cyprus: ${ }^{2}$ Department of Nursing, \\ School of Health Sciences, Cyprus University of Technology, Limassol, Cyprus: ${ }^{3}$ St George University of London \\ Medical School at the University of Nicosia, Nicosia, Cyprus: ${ }^{4} 3$ rd Department of Pediatrics, Attikon University \\ Hospital, University of Athens Medical School, Athens, Greece
}

Submitted 21 May 2013: Final revision received 24 0ctober 2013: Accepted 8 November 2013: First published online 17 January 2014

\begin{abstract}
Objective: To assess vitamin D status among Cypriot adolescents and investigate potential determinants including BMI and body fat percentage (BF\%).

Design: Participants had cross-sectional assessments of serum vitamin D, physical activity, dietary vitamin D intake and sun exposure. Linear and logistic regression models were used to explore the associations of vitamin D with potential predictors. Setting: Hospitals, Cyprus, November 2007-May 2008.

Subjects: Adolescents ( $n$ 671) aged 16-18 years.

Results: Mean serum vitamin D was $22 \cdot 90$ (sD 6.41) ng/ml. Only one in ten children had sufficient levels of vitamin D $(\geq 30 \mathrm{ng} / \mathrm{ml})$, while the prevalence of vitamin D deficiency $(12-20 \mathrm{ng} / \mathrm{ml})$ and severe deficiency $(<12 \mathrm{ng} / \mathrm{ml})$ was $31 \cdot 7 \%$ and $4 \cdot 0 \%$, respectively. Lower vitamin D was associated with winter and spring season, female gender, reduced sun exposure in winter and darker skin. Participants with highest $\mathrm{BMI}$ and $\mathrm{BF} \%$ when compared with a middle reference group had increased adjusted odds of vitamin D insufficiency $(\mathrm{OR}=3 \cdot 00 ; 95 \%$ CI $1 \cdot 21,7 \cdot 45$ and $\mathrm{OR}=$ 5.02; $95 \%$ CI 1.80, 13.97, respectively). A similar pattern, although not as strong, was shown for vitamin D deficiency with $\mathrm{BF} \%(\mathrm{OR}=1 \cdot 81 ; 95 \% \mathrm{CI} 1 \cdot 04,3 \cdot 16)$ and BMI $(\mathrm{OR}=1 \cdot 51 ; 95 \% \mathrm{CI} 0 \cdot 85,2 \cdot 67)$. Participants in the lowest $\mathrm{BMI}$ and $\mathrm{BF} \%$ groups also displayed compromised vitamin D status, suggesting a U-shaped association. Conclusions: Vitamin D deficiency in adolescence is very prevalent in sunny Cyprus, particularly among females, those with darker skin and those with reduced sun exposure in winter. Furthermore, vitamin D status appears to have a U-shaped association with adiposity measures.
\end{abstract}

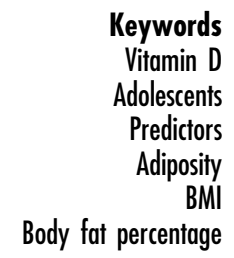

The role of vitamin D in skeletal growth and development is established. An increasing body of observational studies provides evidence on a possible link between inadequate vitamin D status and chronic conditions such as CVD, diabetes and asthma ${ }^{(1,2)}$. This may be particularly important in adolescence, since this is a critical period for growth and development characterised by increasing requirements for minerals and vitamins as well as a period of intense social and behavioural changes. There have been a number of studies on the predictors of vitamin D deficiency in adults and young children ${ }^{(3-8)}$ but information on vitamin D status and its predictors in adolescents is limited ${ }^{(5,6,9,10)}$.

Of particular interest is the association of adiposity with vitamin D. There seems to be some uncertainty in the literature regarding this issue. A number of studies have shown a strong negative linear association between BMI and vitamin D level, mainly in children ${ }^{(6,11,12)}$, while in other studies no such association was identified ${ }^{(3,5,9)}$. Many of these studies have restricted their investigation to the obese ${ }^{(11,13)}$ and unfortunately some did not adjust for known confounding factors such as gender, sun exposure and physical activity ${ }^{(4,9)}$.

BMI is a widely used measure of adiposity; nevertheless, body fat percentage $(\mathrm{BF} \%)$, as estimated by the bio-impedance technique, is a better measure of adipose tissue per se and avoids the confounding caused by bone and muscle mass ${ }^{(14)}$. BF\% correlates well with BMI in children aged 6-9 years but exhibits a reduced degree of correlation with BMI in adolescents, in boys and at the extremes of $\mathrm{BMI}^{(15)}$. To date, only a handful of studies have investigated the nature of the association of both adiposity indices (BMI and BF\%) with vitamin D in healthy 
adolescents across the whole spectrum of adiposity, with some however not adjusting for the effect of potential confounders ${ }^{(5,6,9)}$.

The present study aimed to: (i) assess serum vitamin D levels and status in adolescents in Cyprus, located in the Eastern Mediterranean region at latitude of $35^{\circ} \mathrm{N}$; (ii) indentify predictors of compromised vitamin $\mathrm{D}$ in this geographical setting; and (iii) more specifically, explore the nature of the association of vitamin D with BMI and BF\%.

\section{Methods}

\section{Study population}

The participants in the present study were a sample of adolescents aged 16-18 years who did not report any wheezing or asthma ever (on the International Study of Asthma and Allergies in Childhood (ISAAC) questionnaire) in a previous large, school-based study on risk factors for asthma ${ }^{(16)}$. A stratified random sampling approach was used in order to increase the probability of selection of children at the extremes of BMI change between childhood and adolescence, in line with the scope of a different study. For the purposes of the present study, we focused only on the non-asthmatic population because in the original study asthmatic adolescents were purposely over-represented as a result of the sampling method. The final sample here consisted of 671 non-asthmatic adolescents (response rate $72 \%$ ) who attended the hospital nearest to their residence in three districts of the island of Cyprus (Nicosia, Limassol and Larnaca) between November 2007 and May 2008. They fasted for $12 \mathrm{~h}$ before the appointment and underwent blood sampling, anthropometric measurements and questionnaire assessments of physical activity levels, dietary intake of vitamin D and sun exposure. Parental education was also recorded and the highest level of educational attainment between the two parents was used as a proxy for socio-economic status. The study was approved by the Cyprus National Bioethics Committee, and consent was obtained in writing from the parents or guardians as well as the children themselves upon arrival at each centre.

\section{Measurement of serum 25-hydroxyvitamin D}

Blood specimens were centrifuged at the collection site and serum aliquots were stored at $-80{ }^{\circ} \mathrm{C}$ and subsequently transferred in dry ice to the Research Laboratory of the University of Athens Medical School at Attikon Hospital. Serum levels of 25-hydroxyvitamin D were measured using the enzyme immune assay kit of Immunodiagnostics Systems Ltd, UK. The intra- and inter-assay CV were $<12 \%$.

\section{Antbropometric measurements}

We measured weight, $\mathrm{BF} \%$ and BMI with the use of a portable device (TBF-300 Body Composition Analyser; Tanita Corporation of America, Inc., Arlington Heights, IL, USA) while height was assessed using a portable stadiometer (Seca 208; Vogel \& Halke GmbH \& Co., Hamburg, Germany) to the nearest centimetre. Measurements were taken in the morning with the participant dressed in light clothing, without shoes. If two measurements differed by more than $0.5 \mathrm{~kg}$ for weight or $1 \mathrm{~cm}$ for height, a third measurement was taken.

\section{Assessment of physical activity}

Physical activity was evaluated with the short version of the International Physical Activity Questionnaire (IPAQ), which assesses three types of activity: walking, moderateintensity activities and vigorous-intensity activities ${ }^{(17)}$. Data collected with IPAQ were processed according to the guidelines classifying each participant's physical activity as low, moderate or high ${ }^{(18)}$.

\section{Sun exposure and skin type}

Sun exposure was assessed as self-reported time spent daily in the sun during weekends and holidays for the past 3 years during the winter or summer months, recorded as hours per day in increments of $1 \mathrm{~h} / \mathrm{d}$ to a maximum of $4 \mathrm{~h} / \mathrm{d}^{(7,19)}$. In addition, the participants' habitual use of sun protection (use of sun block creams, clothing, hats) when out in the sun in the summer was recorded as never/rarely, occasionally, most of the time and always/almost always. Finally, trained research assistants classified the participants' skin type as dark, olive, olive/medium, medium/fair and fair.

\section{Dietary intake of vitamin D}

We assessed dietary food intake with the use of a food frequency recall questionnaire (FFQ) adapted to the Greek cuisine ${ }^{(20)}$. The questionnaire recorded the frequency of consumption of foods over the preceding 3 months (per day, week and month) and included food items from twenty-one food categories including cereals, dairy products, meat, fruit and vegetables and dietary supplements. Foods that are a good source of vitamin D such as oily fish and eggs were included in the FFQ. Dietary intake of vitamin D was calculated based on the questionnaire data and using local food composition tables.

\section{Statistical analysis}

Vitamin D status was classified as severe deficiency (serum 25-hydroxyvitamin $\mathrm{D}<12 \mathrm{ng} / \mathrm{ml})$, deficiency (12-20 ng/ml), insufficiency $(20-30 \mathrm{ng} / \mathrm{ml})$ and sufficiency $(\geq 30 \mathrm{ng} / \mathrm{ml})^{(9)}$. The association of mean vitamin $D$ levels and vitamin $D$ deficiency status with potential predictors was investigated in linear and logistic regression models, respectively. Multivariable regression models were used to explore the association between vitamin D and BMI and BF\%, while adjusting for seasonality and potential confounders. Specifically, $\beta$ coefficients of differences in mean vitamin $D$ levels and odds ratios of vitamin D deficiency and insufficiency status were calculated across categories of gender-standardised $Z$-scores of $\mathrm{BMI}$ and $\mathrm{BF} \%$, adjusting 
for seasonality (model 1) and further adjusting for skin type, sun exposure in winter, use of sun protection, physical activity and dietary intake of vitamin D (model 2). In contrast to BMI, there are no generally used percentile charts for $\mathrm{BF} \%$; thus, for both measures of adiposity, we calculated gender-standardised $Z$-scores and contrasted five categories using the middle category as the reference, i.e. $\leq-1,-1$ to $-0.5,-0.5$ to $0.5,0.5$ to 1 and $\geq 1$. In all analyses normalised sampling weights based on inverse probability of selection from the original population were used. Statistical analysis was performed using the statistical software package PASW 18.

\section{Results}

\section{Population characteristics}

Table 1 presents the participant characteristics along with the unadjusted associations of vitamin D levels and vitamin D deficiency status with potential predictors. Among participants, $42 \cdot 8 \%$ were male and on average they were $17 \cdot 0$ (SD $0 \cdot 6$ ) years old (range $15 \cdot 7-18 \cdot 4$ years). The most frequent skin type was olive/medium (69.5\%) with medium/fair (24.9\%) ranking second. As expected, sun exposure was more frequent in the summer with as many as $30.6 \%$ reporting being exposed to the sun for longer than $4 \mathrm{~h} / \mathrm{d}$ during a weekend or holiday as opposed to only $6.0 \%$ in the winter. Sun protection was reportedly used systematically by only a small proportion of the participants $(16.6 \%)$, while as many as $24.7 \%$ reported using rarely or never. Median level of dietary vitamin $\mathrm{D}$ intake was as low as $4 \cdot 1 \mu \mathrm{g} / \mathrm{d}$ (interquartile range $3 \cdot 1-6 \cdot 0 \mu \mathrm{g} / \mathrm{d})$. Finally, more than half of the participants reported low levels of physical activity (52.9\%).

\section{Vitamin D status}

Vitamin D values were normally distributed, with a mean value as low as 22.90 (sD 6.41) ng/ml (range $5 \cdot 80-49 \cdot 00 \mathrm{ng} / \mathrm{ml}$ ). As shown in Fig. 1, the prevalence of vitamin D severe deficiency, deficiency and insufficiency was $4 \cdot 0 \%, 31 \cdot 7 \%$ and $51 \cdot 2 \%$, respectively, whereas only about one in ten children had sufficient vitamin D levels $(13 \cdot 1 \%)$. As expected for individuals living in the northern hemisphere, mean serum vitamin D level (see Fig. 2) was higher in November and decreased gradually over the winter months to reach the lowest level in February. With the exception of a slight dip in May (based on only thirty-six participants), mean vitamin D level started to increase gradually over the spring months, revealing a U-shaped pattern across the 7-month study period.

\section{Predictors for lower vitamin D levels and deficiency status}

Mean vitamin D level was lower in girls than boys $(22 \cdot 23 v$. $23.87 \mathrm{ng} / \mathrm{ml} ; P<0.01)$ and significantly higher in autumn compared with winter and spring seasons $(25 \cdot 86$ v. $22 \cdot 73$ and $22 \cdot 61 \mathrm{ng} / \mathrm{ml}$, respectively; $P=0 \cdot 03$; see Table 1 ). Higher self-reported sun exposure in winter, but not in summer, was associated with increased vitamin D levels ( $P$ value for linear trend $<0 \cdot 01$ ), while participants with darker skin type tended to have lower vitamin D levels than those with lighter skin $(P$ value $=0 \cdot 04)$. Use of sun protection, physical activity levels, parental education and dietary vitamin D intake were not significantly associated with levels of vitamin D. When expressed as vitamin D deficiency (i.e. the proportion of participants with vitamin D levels $12-20 \mathrm{ng} / \mathrm{ml}$ ), a similar pattern was observed in terms of gender, season of blood sampling, sun exposure in winter and skin type (see Table 1). In this case, associations did not always reach statistical significance with the exception of gender, where the odds of vitamin $\mathrm{D}$ deficiency in females compared with males was $\mathrm{OR}=1.52$ (95\% CI $1 \cdot 09,2 \cdot 11)$. The risk of vitamin D deficiency remained significantly raised in females compared with males even after adjusting for BMI $(\mathrm{OR}=1 \cdot 44 ; 95 \% \mathrm{CI}$ 1.02, 2.03; data not shown).

\section{Association of vitamin D levels and deficiency status with BMI and body fat percentage}

Vitamin D levels and vitamin D deficiency or insufficiency across gender-standardised $\mathrm{BMI}$ and $\mathrm{BF} \%$ Z-score categories are shown in Table 2 . The corresponding cut-off values for the gender-specific BMI and BF\% Z-score categories are presented in Table 3. Mean vitamin D level among those with $\mathrm{BMI}$ and $\mathrm{BF} \% Z$-score $\geq 1$ was $3 \cdot 16 \mathrm{ng} / \mathrm{ml}(95 \%$ CI $-4 \cdot 76,-1.56 \mathrm{ng} / \mathrm{ml})$ and $2 \cdot 65 \mathrm{ng} / \mathrm{ml}(95 \% \mathrm{CI}-4 \cdot 29$, $-1.02 \mathrm{ng} / \mathrm{ml}$ ) lower than that of the reference group (i.e. those with $Z$-score between -0.5 and 0.5 ), respectively. Adolescents in the low BMI and BF\% $Z$-score categories also seemed to have lower mean vitamin D levels when compared with the reference category although estimates were not statistically significant. Estimates remained largely unchanged after adjusting for other covariates in multivariable models.

In the case of vitamin D status, the season-adjusted odds for vitamin D deficiency among those with BF\% $Z$-score $\geq 1$ (as compared with the reference group) was $\mathrm{OR}=2 \cdot 02(95 \%$ CI $1 \cdot 22,3 \cdot 33)$ and, although it attenuated slightly after adjusting for all confounders, it remained statistically significant $(\mathrm{OR}=1 \cdot 81 ; 95 \% \mathrm{CI} 1 \cdot 04,3 \cdot 16)$. Likewise, adolescents with BMI $Z$-score $\geq 1$ seemed to be $1 \cdot 7$ times more likely to be vitamin $\mathrm{D}$ deficient $(\mathrm{OR}=$ 1·76; CI $1 \cdot 10,2 \cdot 45)$. Nevertheless, in the case of BMI, the association was no longer statistically significant in the adjusted model $(\mathrm{OR}=1 \cdot 51$; CI 0·85, 2•67). As with mean vitamin D levels analysis, participants in the low BMI and BF\% Z-score categories appeared to have compromised vitamin D levels albeit non-significant when compared with those in the reference group (Table 2). Similarly, results are not so striking for vitamin D deficiency. However, in terms of vitamin D insufficiency there was a clearer U-shaped pattern with both measures of adiposity 
Table 1 Association of serum vitamin D (25-hydroxyvitamin D) levels and vitamin D deficiency with potential predictors among 671 adolescents aged 16-18 years, Cyprus, November 2007-May 2008

\begin{tabular}{|c|c|c|c|c|c|c|c|c|c|}
\hline \multirow[b]{2}{*}{ Variable } & \multirow[b]{2}{*}{ Category } & \multirow{2}{*}{$\begin{array}{c}\text { Proportion of } \\
\text { participants }(\%)^{*}\end{array}$} & \multicolumn{2}{|c|}{ Serum vitamin $D(\mathrm{ng} / \mathrm{ml})$} & \multirow[b]{2}{*}{$P$ valuet } & \multirow{2}{*}{$\begin{array}{l}\text { Proportion of participants with } \\
\text { vitamin D deficiency (\%) }\end{array}$} & \multirow[b]{2}{*}{ Unadjusted OR } & \multirow[b]{2}{*}{$95 \% \mathrm{Cl}$} & \multirow[b]{2}{*}{$P$ value } \\
\hline & & & Mean & SD & & & & & \\
\hline \multirow{2}{*}{ Gender } & Male & $42 \cdot 8$ & $23 \cdot 87$ & $6 \cdot 62$ & \multirow[t]{2}{*}{$<0.01$} & $30 \cdot 2$ & $1 \cdot 00$ & Ref. & \multirow{2}{*}{0.01} \\
\hline & Female & $57 \cdot 2$ & $22 \cdot 23$ & $6 \cdot 19$ & & $39 \cdot 4$ & 1.52 & $1 \cdot 09,2 \cdot 11$ & \\
\hline \multirow[t]{3}{*}{ Season } & Autumn & $11 \cdot 3$ & $25 \cdot 86$ & $6 \cdot 73$ & \multirow[t]{3}{*}{0.03} & $23 \cdot 9$ & $1 \cdot 00$ & Ref. & \multirow[t]{3}{*}{$0 \cdot 17$} \\
\hline & Winter & $50 \cdot 1$ & $22 \cdot 73$ & $6 \cdot 51$ & & $36 \cdot 1$ & $1 \cdot 86$ & $0 \cdot 91,3 \cdot 81$ & \\
\hline & Spring & $38 \cdot 6$ & $22 \cdot 61$ & $6 \cdot 10$ & & $37 \cdot 4$ & 1.97 & $0.95,4.07$ & \\
\hline \multirow[t]{5}{*}{ Sun exposure in summer } & $<1 \mathrm{~h} / \mathrm{d}$ & $2 \cdot 8$ & $22 \cdot 05$ & 6.05 & \multirow[t]{5}{*}{$0 \cdot 25$} & $33 \cdot 3$ & $1 \cdot 00$ & Ref. & \multirow[t]{5}{*}{$0 \cdot 61$} \\
\hline & $1-2 \mathrm{~h} / \mathrm{d}$ & $15 \cdot 8$ & $22 \cdot 58$ & $7 \cdot 13$ & & $37 \cdot 5$ & $1 \cdot 21$ & $0 \cdot 34,4 \cdot 31$ & \\
\hline & $2-3 \mathrm{~h} / \mathrm{d}$ & $25 \cdot 9$ & $22 \cdot 57$ & $6 \cdot 25$ & & $37 \cdot 6$ & $1 \cdot 21$ & $0 \cdot 35,4 \cdot 22$ & \\
\hline & $3-4 \mathrm{~h} / \mathrm{d}$ & $24 \cdot 8$ & $23 \cdot 07$ & $5 \cdot 88$ & & $32 \cdot 9$ & 0.97 & $0 \cdot 28,3 \cdot 40$ & \\
\hline & $>4 \mathrm{~h} / \mathrm{d}$ & $30 \cdot 6$ & $23 \cdot 22$ & $6 \cdot 63$ & & $35 \cdot 8$ & $1 \cdot 10$ & $0 \cdot 32,3 \cdot 83$ & \\
\hline \multirow[t]{5}{*}{ Sun exposure in winter } & $<1 \mathrm{~h} / \mathrm{d}$ & $21 \cdot 6$ & $22 \cdot 16$ & $6 \cdot 62$ & \multirow[t]{5}{*}{$<0.01$} & $36 \cdot 4$ & $1 \cdot 00$ & Ref. & \multirow[t]{5}{*}{$0 \cdot 02$} \\
\hline & $1-2 \mathrm{~h} / \mathrm{d}$ & $39 \cdot 2$ & $22 \cdot 31$ & $6 \cdot 06$ & & $42 \cdot 0$ & $1 \cdot 26$ & $0.83,1.92$ & \\
\hline & $2-3 \mathrm{~h} / \mathrm{d}$ & $21 \cdot 9$ & $23 \cdot 69$ & $6 \cdot 67$ & & $28 \cdot 7$ & $0 \cdot 71$ & $0 \cdot 43,1 \cdot 17$ & \\
\hline & $3-4 \mathrm{~h} / \mathrm{d}$ & $11 \cdot 4$ & 23.98 & $5 \cdot 83$ & & $29 \cdot 7$ & 0.73 & $0 \cdot 40,1 \cdot 35$ & \\
\hline & $>4 \mathrm{~h} / \mathrm{d}$ & $6 \cdot 0$ & $25 \cdot 13$ & $7 \cdot 52$ & & $21 \cdot 9$ & 0.52 & $0 \cdot 21,1 \cdot 26$ & \\
\hline \multirow[t]{4}{*}{ Use of sun protection } & Never/rarely & $24 \cdot 7$ & $22 \cdot 75$ & $6 \cdot 10$ & \multirow[t]{4}{*}{$0 \cdot 36$} & $38 \cdot 7$ & $1 \cdot 00$ & Ref. & \multirow[t]{4}{*}{$0 \cdot 14$} \\
\hline & Occasionally & $37 \cdot 2$ & $22 \cdot 88$ & $6 \cdot 88$ & & $37 \cdot 0$ & 0.94 & $0.62,1 \cdot 43$ & \\
\hline & Most of the time & $21 \cdot 5$ & $22 \cdot 16$ & $5 \cdot 79$ & & $36 \cdot 3$ & 0.90 & $0.56,1.44$ & \\
\hline & Always/almost always & $16 \cdot 6$ & 23.93 & $6 \cdot 54$ & & $29 \cdot 2$ & 0.66 & $0 \cdot 39,1 \cdot 11$ & \\
\hline \multirow[t]{4}{*}{ Skin type } & Olive & $4 \cdot 0$ & $23 \cdot 42$ & $8 \cdot 84$ & \multirow[t]{4}{*}{0.04} & $30 \cdot 0$ & $1 \cdot 00$ & Ref. & \multirow[t]{4}{*}{0.08} \\
\hline & Olive/medium & $69 \cdot 5$ & $22 \cdot 48$ & $6 \cdot 23$ & & $38 \cdot 2$ & $1 \cdot 42$ & $0.53,3.82$ & \\
\hline & Medium/fair & $24 \cdot 9$ & $23 \cdot 83$ & $6 \cdot 59$ & & $29 \cdot 5$ & 0.97 & $0 \cdot 35,2 \cdot 70$ & \\
\hline & Fair & $1 \cdot 5$ & $24 \cdot 30$ & $5 \cdot 37$ & & $25 \cdot 0$ & 0.56 & $0 \cdot 08,4 \cdot 10$ & \\
\hline \multirow[t]{3}{*}{ Exercise level (IPAQ) } & Low & $52 \cdot 9$ & $22 \cdot 75$ & $6 \cdot 57$ & \multirow[t]{3}{*}{$0 \cdot 40$} & $37 \cdot 0$ & $1 \cdot 00$ & Ref. & 0.47 \\
\hline & Moderate & $34 \cdot 0$ & $22 \cdot 88$ & $6 \cdot 23$ & & $33 \cdot 2$ & 0.83 & $0.57,1 \cdot 20$ & \\
\hline & High & $13 \cdot 1$ & $23 \cdot 47$ & $6 \cdot 07$ & & $34 \cdot 5$ & 0.90 & $0.55,1.49$ & \\
\hline Highest level of parental education & Elementary & $3 \cdot 0$ & $22 \cdot 68$ & $7 \cdot 44$ & 0.62 & $45 \cdot 5$ & $1 \cdot 00$ & Ref. & $0 \cdot 40$ \\
\hline & Secondary & $61 \cdot 9$ & $22 \cdot 99$ & $6 \cdot 50$ & & $33 \cdot 0$ & 0.58 & $0 \cdot 24,1 \cdot 38$ & \\
\hline & Tertiary & $35 \cdot 2$ & $22 \cdot 65$ & $6 \cdot 16$ & & $39 \cdot 1$ & 0.75 & $0 \cdot 31,1 \cdot 82$ & \\
\hline
\end{tabular}

IPAQ, International Physical Activity Questionnaire; Ref., referent category.

*The,

tWith the exception of gender where $P$ value for the difference is reported, in all other cases $P$ value for the linear trend is reported. 

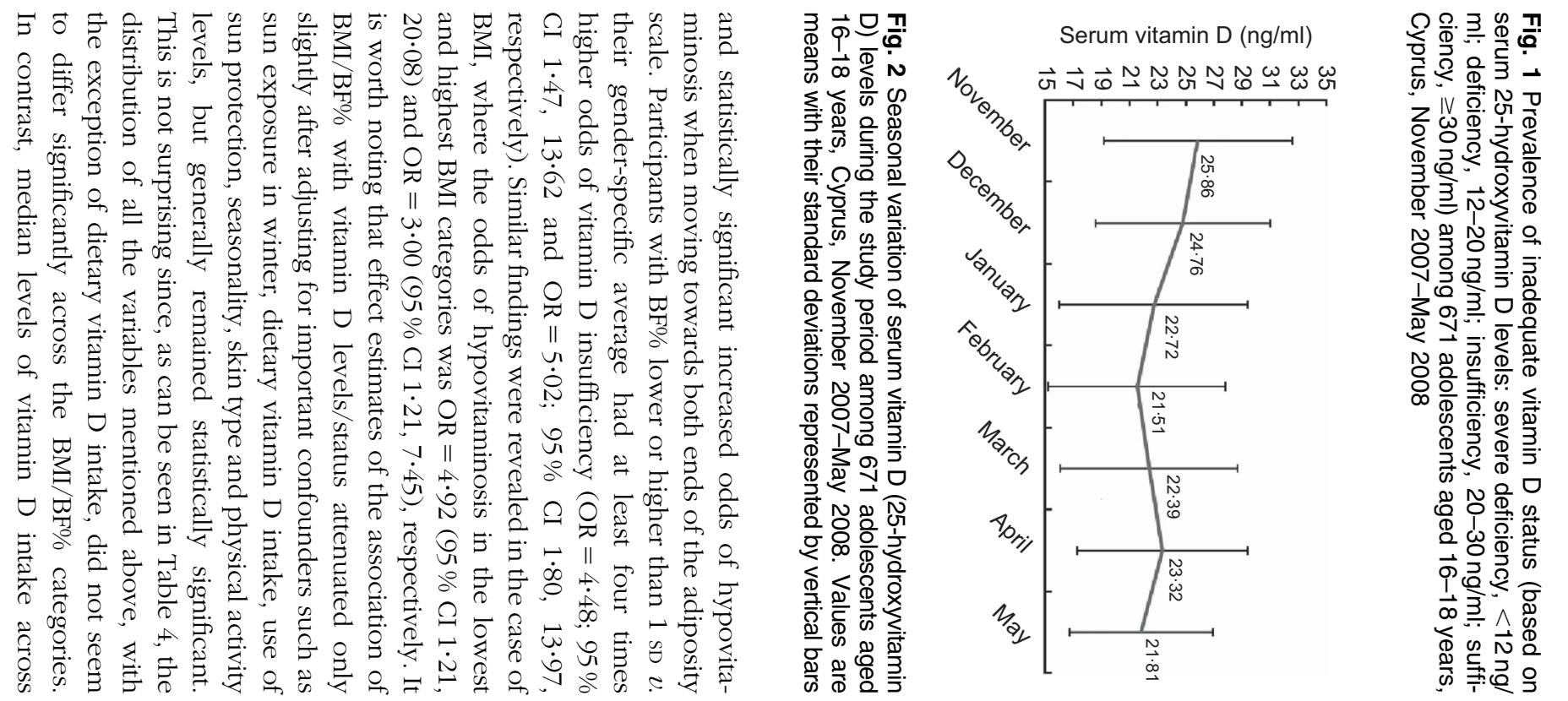

Table 2 Association of serum vitamin D (25-hydroxyvitamin D) levels, vitamin D deficiency and vitamin D insufficiency with BMI and body fat percentage (BF\%) among 671 adolescents aged 16-18 years, Cyprus, November 2007-May 2008

\begin{tabular}{|c|c|c|c|c|c|c|c|c|c|c|c|c|c|c|c|c|}
\hline \multirow{3}{*}{$\begin{array}{l}\text { Gender-standardised } \\
Z \text {-score category }\end{array}$} & \multicolumn{6}{|c|}{ Mean vitamin D levels } & \multicolumn{5}{|c|}{ Vitamin D deficiency } & \multicolumn{5}{|c|}{ Vitamin D insufficiency } \\
\hline & \multicolumn{2}{|c|}{$\begin{array}{l}\text { Vitamin D } \\
(\mathrm{ng} / \mathrm{ml})\end{array}$} & \multicolumn{2}{|r|}{$\begin{array}{l}\text { Adjusted } \\
\text { model } 1^{*}\end{array}$} & \multicolumn{2}{|r|}{$\begin{array}{l}\text { Adjusted } \\
\text { model } 2 \dagger\end{array}$} & \multirow{2}{*}{$\begin{array}{l}\text { Percentage of vitamin D } \\
\text { deficiency }(\%)\end{array}$} & \multicolumn{2}{|c|}{$\begin{array}{l}\text { Adjusted } \\
\text { model } 1^{*}\end{array}$} & \multicolumn{2}{|c|}{$\begin{array}{l}\text { Adjusted } \\
\text { model } 2+\end{array}$} & \multirow{2}{*}{$\begin{array}{l}\text { Percentage of vitamin D } \\
\text { insufficiency (\%) }\end{array}$} & \multicolumn{2}{|r|}{$\begin{array}{l}\text { Adjusted } \\
\text { model } 1^{*}\end{array}$} & \multicolumn{2}{|r|}{$\begin{array}{l}\text { Adjusted } \\
\text { model } 2+\end{array}$} \\
\hline & Mean & SD & $\beta$ & $95 \% \mathrm{Cl}$ & $\beta$ & $95 \% \mathrm{Cl}$ & & OR & $95 \% \mathrm{Cl}$ & OR & $95 \% \mathrm{Cl}$ & & OR & $95 \% \mathrm{Cl}$ & OR & $95 \% \mathrm{Cl}$ \\
\hline \multicolumn{17}{|l|}{$\mathrm{BF} \%$} \\
\hline$\leq-1$ & $22 \cdot 28$ & $5 \cdot 73$ & -1.35 & $-2 \cdot 85,0 \cdot 17$ & $-1 \cdot 38$ & $-2 \cdot 95,0 \cdot 20$ & $30 \cdot 3$ & $1 \cdot 32$ & $0 \cdot 80,2 \cdot 39$ & $1 \cdot 17$ & $0.68,2.02$ & $93 \cdot 4$ & $4 \cdot 33$ & $1 \cdot 43,13.09$ & $4 \cdot 48$ & $1.47,13.62$ \\
\hline-1 to -0.5 & 22.69 & $6 \cdot 78$ & -0.96 & $-2 \cdot 30,0 \cdot 37$ & -0.82 & $-2 \cdot 24,0 \cdot 60$ & $37 \cdot 8$ & 1.39 & $0 \cdot 88,2 \cdot 17$ & 1.33 & $0 \cdot 82,2 \cdot 17$ & $85 \cdot 9$ & $1 \cdot 16$ & $0 \cdot 59,2 \cdot 24$ & $1 \cdot 18$ & $0 \cdot 61,2 \cdot 30$ \\
\hline-0.5 to 0.5 & 23.90 & $6 \cdot 48$ & 1.00 & Ref. & 1.00 & Ref. & $39 \cdot 1$ & 1.00 & Ref. & 1.00 & Ref. & $80 \cdot 8$ & 1.00 & Ref. & 1.00 & Ref. \\
\hline 0.5 to 1 & $22 \cdot 88$ & $6 \cdot 60$ & -1.39 & $-3.00,0.22$ & -1.65 & $-3.39,0.09$ & 35.5 & $1 \cdot 42$ & $0 \cdot 82,2 \cdot 46$ & $1 \cdot 40$ & $0.77,2.58$ & $83 \cdot 1$ & 1.57 & $0 \cdot 71,3 \cdot 51$ & 1.65 & $0.73,3.73$ \\
\hline$\geq 1$ & $21 \cdot 40$ & 5.89 & $-3 \cdot 18$ & $-4 \cdot 65,-1 \cdot 70$ & $-3 \cdot 16$ & $-4 \cdot 76,-1 \cdot 56$ & $42 \cdot 0$ & $2 \cdot 02$ & $1 \cdot 22,3.33$ & $1 \cdot 81$ & $1 \cdot 04,3 \cdot 16$ & 94.9 & $5 \cdot 14$ & $1 \cdot 86,14 \cdot 25$ & $5 \cdot 02$ & $1.80,13.97$ \\
\hline \multicolumn{17}{|c|}{ 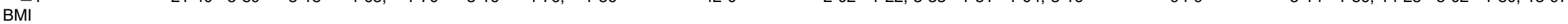 } \\
\hline$\leq-1$ & $22 \cdot 79$ & $5 \cdot 87$ & -0.55 & $-1 \cdot 27,1 \cdot 76$ & -0.61 & $-2 \cdot 34,1 \cdot 13$ & $34 \cdot 2$ & $1 \cdot 13$ & $0.65,1.97$ & 0.97 & $0.53,1.77$ & 94.5 & $4 \cdot 52$ & $1 \cdot 12,18 \cdot 23$ & 4.92 & $1 \cdot 21,20 \cdot 08$ \\
\hline-1 to -0.5 & $22 \cdot 10$ & $6 \cdot 69$ & -1.31 & $-2.59,-0.03$ & -0.65 & $-2 \cdot 01,0 \cdot 70$ & $45 \cdot 0$ & 1.85 & $1 \cdot 21,2 \cdot 83$ & $1 \cdot 45$ & $0 \cdot 92,2 \cdot 28$ & $83 \cdot 9$ & 0.88 & $0.48,1.63$ & 0.85 & $0.46,1.58$ \\
\hline-0.5 to 0.5 & $23 \cdot 77$ & $6 \cdot 31$ & 1.00 & Ref. & 1.00 & Ref. & $29 \cdot 5$ & 1.00 & Ref. & 1.00 & Ref. & $83 \cdot 8$ & 1.00 & Ref. & 1.00 & Ref. \\
\hline 0.5 to 1 & $23 \cdot 14$ & 6.58 & $-1 \cdot 24$ & $-2 \cdot 88,0.39$ & -1.54 & $-3 \cdot 35,0 \cdot 27$ & $37 \cdot 3$ & 1.67 & $0.96,2.92$ & $1 \cdot 44$ & $0 \cdot 77,2 \cdot 72$ & $82 \cdot 7$ & $2 \cdot 10$ & $0 \cdot 83,5 \cdot 33$ & $2 \cdot 23$ & $0.86,5 \cdot 78$ \\
\hline$\geq 1$ & $21 \cdot 80$ & $6 \cdot 32$ & -2.65 & $-4 \cdot 19,-1 \cdot 11$ & -2.65 & $-4 \cdot 29,-1 \cdot 02$ & $37 \cdot 8$ & $1 \cdot 76$ & $1 \cdot 10,2 \cdot 45$ & 1.51 & $0.85,2.67$ & $92 \cdot 2$ & $2 \cdot 89$ & $1 \cdot 18,7 \cdot 09$ & 3.00 & $1 \cdot 21,7 \cdot 45$ \\
\hline
\end{tabular}


Table 3 Cut-off values for the corresponding BMI and body fat percentage (BF\%) Z-score categories, stratified by gender, among 671 adolescents aged 16-18 years, Cyprus, November 2007-May 2008

\begin{tabular}{lcc}
\hline Gender-standardised Z-score category & Boys' range of values & Girls' range of values \\
\hline BF\% & & $<17 \cdot 55$ \\
$\quad \leq-1$ & $<7 \cdot 95$ & $17 \cdot 56-21 \cdot 10$ \\
-1 to -0.5 & $7 \cdot 96-11 \cdot 75$ & $21 \cdot 11-28 \cdot 25$ \\
$-0 \cdot 5$ to $0 \cdot 5$ & $11 \cdot 76-19 \cdot 25$ & $28 \cdot 26-31 \cdot 85$ \\
0.5 to 1 & $19 \cdot 26-22 \cdot 90$ & $31 \cdot 86-45 \cdot 50$ \\
$\geq 1$ & $22 \cdot 91-51 \cdot 85$ & $<18 \cdot 12$ \\
BMI & & $18 \cdot 13-19 \cdot 82$ \\
$\leq-1$ & $19 \cdot 18-21 \cdot 29$ & $19 \cdot 83-23 \cdot 23$ \\
-1 to -0.5 & $21 \cdot 30-25 \cdot 55$ & $23 \cdot 24-24 \cdot 80$ \\
-0.5 to 0.5 & $25 \cdot 26-27 \cdot 60$ & $24 \cdot 80-37 \cdot 21$ \\
0.5 to 1 & $27 \cdot 61-47 \cdot 83$ & \\
$\geq 1$ &
\end{tabular}

BMI cut-off values in $\mathrm{kg} / \mathrm{m}^{2}$; BF\% cut-off values in $\%$.

the $\mathrm{BMI} / \mathrm{BF} \%$ categories seemed to mirror the observed pattern of association between serum levels of vitamin D and adiposity measures even though they cannot totally explain it.

\section{Discussion}

\section{Main findings}

In the present cross-sectional study, we have shown that one in three adolescents is vitamin D deficient in a sunny place like Cyprus while only one in ten seems to have a sufficient vitamin D level. Female gender, darker skin type and low sun exposure in winter are significant predictors of lower mean vitamin D levels and deficiency status. Adolescents with the highest $\mathrm{BMI}$ and $\mathrm{BF} \%$ have statistically significantly lower vitamin D levels and increased odds for vitamin D deficiency and insufficiency, which does not appear to be explained by sun exposure or dietary intake of vitamin D. Quite interestingly, we also found that irrespective of the measure of adiposity used those in the lowest BMI and BF\% categories also appear more likely to be vitamin D insufficient.

\section{Vitamin D levels and status}

It is now widely accepted that vitamin D deficiency is becoming a public health problem worldwide ${ }^{(4-6,9,12,21)}$ and has been shown to be important even in countries with abundant sun exposure ${ }^{(4,6,21,22)}$. In the present study vitamin D levels were measured mostly over the winter and spring months and, as a result, possibly capture the lowest end of the spectrum. Nevertheless, mean vitamin D levels among Cypriot adolescents appear comparable to those reported in a recent multi-centre European study in adolescents (the Healthy Lifestyle in Europe by Nutrition in Adolescence (HELENA) Study) ${ }^{(9)}$ which however included participants from a wider age spectrum and a number of Northern European countries. Findings are also consistent with those reported in a study of adolescents from the island of Crete who had their vitamin D levels measured over the winter season ${ }^{(9)}$. Elsewhere, in other sunny parts of the world, vitamin D deficiency is also becoming more prevalent. In Brazil, adolescents were shown to have mean vitamin D levels just above the deficiency cut-off point while the prevalence of vitamin D insufficiency was as high as $60 \%{ }^{(23)}$. Similarly, a study in Beirut showed that one in two children aged 10-16 years was vitamin D insufficient ${ }^{(24)}$, while in Qatar the prevalence of vitamin D deficiency this age group appeared to be over $60 \%$ during the autumn and winter period ${ }^{(25)}$. Thus our findings confirm that vitamin D deficiency is also becoming very prevalent in the Mediterranean region, at least during the winter months ${ }^{(9)}$.

\section{Predictors of vitamin D levels and status}

Monthly mean levels of vitamin D have been described to follow a sinusoidal pattern throughout the year, generally peaking at the beginning of autumn and displaying the lowest values at the beginning of spring in the northern hemisphere ${ }^{(26)}$. This is largely consistent with the pattern observed over the 6-month period in the present study, which shows vitamin D levels declining steadily over the winter months to reach the lowest values around February, when they start rising again over the spring months. Also consistent with the literature, females were shown to be at increased risk of inadequate vitamin D status $^{(3,6,27,28)}$. As expected, we found lower vitamin D levels among those with darker skin complexions as well as those reporting spending less time in the sun in winter. In contrast, no similar association was observed with reported sun exposure in the summer, as perhaps even short exposure to the sun during the summer is sufficient to synthesise adequate levels of vitamin $D^{(29)}$. Surprisingly, frequent use of sun protection did not seem to affect vitamin D levels significantly. If anything, it seemed that vitamin D levels were higher among those who reported more frequent use. This has also been described in a study of 7500 children aged 7-13 years in the $\mathrm{UK}^{(3)}$ and was attributed to the fact that children who use sun protection tend to spend more time outdoors. Finally, 
vigorous activity and fitness have been shown in previous studies to be positively associated with vitamin D levels ${ }^{(6,7)}$. We did not observe such an association; however, the data used in our study did not refer to fitness levels but to intensity of physical activity, which in previous studies has not always been found to correlate with vitamin D status $^{(7,8)}$.

\section{Association of BMI and body fat percentage with vitamin $D$ levels and status}

Irrespective of the adiposity measure used, serum vitamin $\mathrm{D}$ levels appeared lower by an average of $2-3 \mathrm{ng} / \mathrm{ml}$ among those in the higher $Z$-score categories. For BMI, similar results have been reported previously ${ }^{(8,12)}$. For instance, a study of 237 children in the USA compared levels between obese (BMI $>95$ th percentile) and non-obese children aged 8-18 years and reported a difference in the range of $3 \cdot 3 \mathrm{ng} / \mathrm{ml}^{(12)}$. Similarly, a recent study by Oliveira et al., which investigated vitamin D levels in 160 normal-weight and overweight adolescents aged 15-17 years in Brazil, showed that serum vitamin D levels were significantly lower among overweight compared with normal-weight adolescents and in those with excess fat mass ${ }^{(30)}$. Furthermore, the odds of vitamin D deficiency and insufficiency were raised significantly in the higher BMI and BF\% $Z$-score categories, which include those with BMI and $\mathrm{BF} \%$ values above the 85th and/or 95th percentile as compared with the Center for Disease Control and Prevention BMI charts and published body fat reference curves in children (Table 3$)^{(27)}$. Vitamin D inadequacy among obese individuals of all ages including adolescents has been described by several studies ${ }^{(13,31-33)}$. This is attributed to the decreased bioavailability of vitamin $\mathrm{D}$ in the obese due to sequestration in body fat stores ${ }^{(34)}$. Indeed, slightly stronger associations were observed with respect to $\mathrm{BF} \%$ since this is a better indicator of adiposity in the high BMI range. These associations did not seem to be confounded by sun exposure, physical activity and dietary intake of vitamin D. Similar to our results, daily sunscreen use and duration of physical activity in sunlight did not seem to differ across vitamin $\mathrm{D}$ levels and between adolescents with and without excess fat in the Brazilian study and therefore could not explain the observed vitamin D-adiposity association ${ }^{(30)}$. This finding is also consistent with studies with elderly and young adult populations ${ }^{(35-37)}$.

The negative association of vitamin D with high BMI and body fat measures is well documented and appears to be more or less consistent across studies in different age groups ${ }^{(11,36)}$. Nevertheless, evidence on the association of vitamin $\mathrm{D}$ with adiposity measures beyond the obese status and across the BMI range is conflicting. For example, a cross-sectional study of 559 adolescents aged 14-18 years in the USA has shown a small inverse linear relationship between serum vitamin $\mathrm{D}$ levels and total fat mass assessed by dual-energy X-ray absorptiometry ${ }^{(6)}$ 
while, in contrast, a study in adolescent girls ${ }^{(38)}$ did not find any association. Similarly, Tolppanen et al. found no association between BMI and vitamin D deficiency status after adjusting for possible confounders ${ }^{(3)}$ while in a study of 382 healthy children and adolescents in the USA fat mass was not independently associated with vitamin $\mathrm{D}$ status ${ }^{(5)}$. In the multi-centre HELENA study, an overall small to moderate negative correlation of BMI $Z$-score with vitamin $\mathrm{D}$ concentration was observed while, in contrast, vitamin $\mathrm{D}$ was shown to be positively associated with body fat in girls ${ }^{(39)}$. The fact that there is no consensus on the relationship of vitamin $\mathrm{D}$ with adiposity measures in general population studies might suggest differences in the association across the spectrum of adiposity.

In the present study, we have observed that the lowest $Z$-score category of either measure of adiposity seems to also be at a high risk of vitamin D insufficiency, and in fact the effect appears comparable to that in the obese. Similarly, a population study of 1766 adults over 65 years of age in England reported significantly higher odds of vitamin D deficiency in people with BMI $<25 \cdot 0 \mathrm{~kg} / \mathrm{m}^{2(40)}$. In the HELENA study, underweight adolescent girls (BMI $<18.5 \mathrm{~kg} / \mathrm{m}^{2}$ ) had lower vitamin D levels compared with all other BMI categories including the obese. In fact, the authors of the study provided evidence to suggest that there is an interaction between BMI and physical fitness since both boys and girls with low BMI $\left(<18.5 \mathrm{~kg} / \mathrm{m}^{2}\right)$ and lower physical fitness seemed to have more compromised vitamin D status ${ }^{(41)}$. Furthermore, in a study examining the bioavailability of vitamin $\mathrm{D}$ in adolescent girls with normal BMI and those with anorexia nervosa, vitamin $\mathrm{D}$ was not correlated with body fat measures ${ }^{(42)}$.

Our findings suggest a possible U-shaped pattern of association of BMI and BF\% with vitamin D which becomes more pronounced in the case of vitamin $\mathrm{D}$ insufficiency. This association holds even after adjusting for potential confounders such as sun exposure, skin type, use of sun protection, physical activity, parental education and vitamin D intake. Vitamin D intake seemed to reflect the lower vitamin $\mathrm{D}$ status in the lower and higher $\mathrm{BMI} / \mathrm{BF} \%$ categories but could not totally explain the U-shaped association. Of course, there is always the possibility of residual confounding (especially due to the self-reported nature of many of the variables considered), as well as the potential contribution of variables not considered here, such general health status. Indeed, the U-shaped pattern in the association between adiposity and vitamin D status as described in our study mirrors the pattern observed between $\mathrm{BMI}$ or $\mathrm{BF} \%$ and mortality or morbidity for a number of diseases in all age groups, including adolescents ${ }^{(43-45)}$. Baumgartner et al. in their review report the lack of studies on the relationship of low BMI and $\mathrm{BF} \%$ with morbidity and mortality ${ }^{(45)}$ and comment on the fact that reported associations between underweight and chronic diseases often do not have a plausible physiological explanation. In the case of vitamin $\mathrm{D}$, a possible explanation behind the increased risk of hypovitaminosis in the underweight and obese could be its reduced bioavailability at the extremes of BMI. More specifically, it has been shown that in individuals with BMI $>25 \cdot 0 \mathrm{~kg} / \mathrm{m}^{2}$, there is a strong negative correlation between peak serum vitamin D and increasing BMI after ingestion of vitamin $\mathrm{D}^{(34)}$. In contrast, in individuals in the BMI range $<25 \cdot 0 \mathrm{~kg} / \mathrm{m}^{2}$, peak serum levels of vitamin D seem to be increasing with increasing BMI and/or $\mathrm{BF} \%{ }^{(42)}$. Nevertheless, further longitudinal studies are needed to investigate the behaviour and role of vitamin D beyond the normal weight and body fat spectrum, especially in the underweight population.

The study findings underline the need for health professionals to be aware of the high prevalence of inadequate vitamin D status in sunny places especially in winter and the individual characteristics of people at risk. In terms of clinical practice, children should be encouraged to practise safe sun exposure (i.e. sun exposure under UV index <3) to avoid increasing risk for skin cancer and whenever this is not enough to maintain sufficient vitamin D levels, vitamin D supplements or food fortification might be appropriate.

\section{Limitations}

The present study is the first prevalence study of inadequate vitamin D status among Cypriot adolescents. No causal inferences can be made with regard to the role of any of the factors studied in the development of vitamin D deficiency due to the cross-sectional design of the study. Nevertheless, the observed associations are largely supported by the physiology of vitamin D synthesis and are consistent with the findings of previous studies in other age groups and populations $s^{(3,5,7,22)}$. The fact that self-reported measures of sun exposure and physical activity levels were used is also a limitation, even though this is not uncommon in most previous studies. Furthermore, the sample was drawn from a cohort of adolescents that excluded those with wheezing symptoms and asthma diagnosis, and thus it is not entirely representative of the general population. Nevertheless, asthmatics have been shown to have lower levels of vitamin $\mathrm{D}$ than non-asthmatics ${ }^{(46)}$. Hence, the prevalence of vitamin D status reported here may in fact be an underestimate of the prevalence in the general population. Finally, parental education was used as a proxy for socio-economic status due to lack of alternative indicators; nevertheless, this has been shown to have a comparable association with vitamin D level as other socio-economic indicators ${ }^{(3)}$.

There are also a number of strengths in the present study. First, two adiposity indicators, BMI and BF\%, were used to investigate the association of adiposity with vitamin D levels and status. Furthermore, we looked at this association across the whole spectrum of adiposity. Previous studies have generally either looked at this 
association among the obese only ${ }^{(11,13,31)}$, while studies that have expanded their investigation beyond the high end of the spectrum have included underweight individuals within the BMI $<25 \cdot 0 \mathrm{~kg} / \mathrm{m}^{2}$ category or assumed that the relationship is linear ${ }^{(3-6,30,38)}$. The present study has specifically looked at vitamin D status at the lower end of the $\mathrm{BMI} / \mathrm{BF} \%$ spectrum and has provided evidence that people within the lower end of adiposity might also have compromised vitamin D levels.

\section{Conclusion}

Vitamin D deficiency is an important public health problem even in sunny places like Cyprus. Our study has confirmed that female gender, darker skin type, low sun exposure and obesity are significant predictors of lower vitamin D levels in adolescents, in line with findings from previous studies. Furthermore, the study has provided evidence to suggest that individuals in the lowest BMI and BF\% categories also appear more likely to be vitamin D insufficient and proposed a U-shaped association between vitamin $\mathrm{D}$ and adiposity measures, a novel finding that merits further investigation.

\section{Acknowledgements}

Sources of funding: This work was co-funded by the European Regional Development Fund and the Republic of Cyprus through the Cyprus Research Promotion

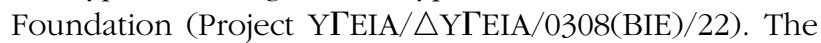
sponsors had no role in the design, analysis or writing of this article. Conflict of interest: The authors have no conflict of interest to report. Ethics: The study was approved by the Cyprus National Bioethics Committee. Authors' contribution: O.K. coordinated the study, performed the statistical analysis and prepared the first draft of the manuscript. P.K.Y. conceived of and designed the study and secured the funding through the Cyprus Research Promotion Foundation. A.P. supervised analysis of the vitamin D samples and assisted in the coordination of the study. P.K.Y. and N.M. assisted in drafting and revising the manuscript. N.M. is the main $\mathrm{PhD}$ advisor of the first author (O.K.). P.Y., V.R. and C.K. are members of the $\mathrm{PhD}$ advisory committee and were involved in the overall supervision of the study. D.L. advised with the statistical analysis. P.N. and A.P. critically revised the manuscript. All authors have read and approved the final version of the manuscript.

\section{References}

1. Holick MF (2004) Sunlight and vitamin D for bone health and prevention of autoimmune diseases, cancers, and cardiovascular disease. Am J Clin Nutr 80, 6 Suppl., 1678S-1688S.
2. Thacher TD \& Clarke BL (2011) Vitamin D insufficiency. Mayo Clinic Proc 86, 50-60.

3. Tolppanen AM, Fraser A, Fraser WD et al. (2012) Risk factors for variation in 25-hydroxyvitamin $\mathrm{D}(3)$ and $\mathrm{D}(2)$ concentrations and vitamin D deficiency in children. J Clin Endocrinol Metab 97, 1202-1210.

4. Poopedi MA, Norris SA \& Pettifor JM (2010) Factors influencing the vitamin D status of 10-year-old urban South African children. Public Health Nutr 14, 334-339.

5. Weng FL, Shults J, Leonard MB et al. (2007) Risk factors for low serum 25-hydroxyvitamin D concentrations in otherwise healthy children and adolescents. Am J Clin Nutr 86, 150-158.

6. Dong Y, Pollock N, Stallmann-Jorgensen IS et al. (2010) Low 25-hydroxyvitamin $\mathrm{D}$ levels in adolescents: race, season, adiposity, physical activity, and fitness. Pediatrics 125, 1104-1111.

7. Jones G, Blizzard C, Riley M et al. (1999) Vitamin D levels in prepubertal children in Southern Tasmania: prevalence and determinants. Eur J Clin Nutr 53, 824-829.

8. Elizondo-Montemayor L, Ugalde-Casas PA, Serrano-González M et al. (2012) Serum 25-hydroxyvitamin D concentration, life factors and obesity in Mexican children. Obesity (Silver Spring) 18, 1805-1811.

9. González-Gross M, Valtuena J, Breidenassel C et al. (2012) Vitamin D status among adolescents in Europe: the Healthy Lifestyle in Europe by Nutrition in Adolescence study. Br J Nutr 107, 755-764.

10. Valtueña J, Breidenassel C, Folle J et al. (2011) Retinol, $\beta$-carotene, $\alpha$-tocopherol and vitamin D status in European adolescents; regional differences an variability: a review. Nutr Hosp 26, 280-288.

11. Lenders CM, Feldman HA, Von Scheven E et al. (2009) Relation of body fat indexes to vitamin D status and deficiency among obese adolescents. Am J Clin Nutr 90 , 459-467.

12. Rajakumar K, de las Heras J, Chen TC et al. (2011) Vitamin D status, adiposity, and lipids in black American and Caucasian children. J Clin Endocrinol Metab 96, 1560-1567.

13. Garanty-Bogacka B, Syrenicz M, Goral J et al. (2011) Serum 25-hydroxyvitamin D (25-OH-D) in obese adolescents. Endokrynol Pol 62, 506-511.

14. Prentice AM \& Jebb SA (2001) Beyond body mass index. Obes Rev 2, 141-147.

15. Widhalm K, Schönegger K, Huemer C et al. (2001) Does the BMI reflect body fat in obese children and adolescents? A study using the TOBEC method. Int J Obes Relat Metab Disord 25, 279-285.

16. Yiallouros PK, Savva S, Kolokotroni O et al. (2012) Low serum high-density lipoprotein cholesterol in childhood is associated with adolescent asthma. Clin Exp Allergy 42, 423-432.

17. Hagströmer $M$, Bergman $P$, De Bourdeaudhuij I et al. (2008) Concurrent validity of a modified version of the International Physical Activity Questionnaire (IPAQ-A) in European adolescents: The HELENA Study. Int J Obes (Lond) 32, Suppl. 5, S42-S48.

18. International Physical Activity Questionnaire (2005) Guidelines for Data Processing and Analysis of the International Physical Activity Questionnaire. http://www. ipaq.ki.se/scoring.pdf (accessed February 2013).

19. Dwyer T, Blizzard L, Gies P et al. (1996) Assessment of habitual sun exposure in adolescents via questionnaire - a comparison with objective measurement using polysulphone badges. Melanoma Res 6, 231-239.

20. Chatzi L, Melaki V, Sarri K et al. (2011) Dietary patterns during pregnancy and the risk of postpartum depression: the mother-child 'Rhea' cohort in Crete, Greece. Public Health Nutr 14, 1663-1670. 
21. Al-Othman A, Al-Musharaf S, Al-Daghri NM et al. (2012) Effect of physical activity and sun exposure on vitamin D status of Saudi children and adolescents. BMC Pediatr 12, 92.

22. Levis S, Gomez A, Jimenez C et al. (2005) Vitamin D deficiency and seasonal variation in an adult South Florida population. J Clin Endocrinol Metab 90, 1557-1562.

23. Peters BSE, dos Santos LC, Fisberg M et al. (2009) Prevalence of vitamin D insufficiency in Brazilian adolescents. Ann Nutr Metab 54, 15-21.

24. Fuleihan GE, Nabulsi M, Choucair M et al. (2001) Hypovitaminosis D in healthy schoolchildren. Pediatrics 107, e53

25. Bener A, Al-Ali M \& Hoffmann GF (2008) Vitamin D deficiency in healthy children in a sunny country: associated factors. Int J Food Sci Nutr 60, 60-70.

26. Shoben AB, Kestenbaum B, Levin G et al. (2011) Seasonal variation in 25-hydroxyvitamin $\mathrm{D}$ concentrations in the cardiovascular health study. Am J Epidemiol 174, 1363-1372.

27. McCarthy H, Cole T, Fry T et al. (2006) Body fat reference curves for children. Int J Obes (Lond) 30, 598-602.

28. Harkness LS \& Cromer BA (2005) Vitamin D deficiency in adolescent females. J Adolesc Health 37, 75.

29. Holick MF \& Jenkins M (2005) The UV Advantage. New York: iBooks.

30. Oliveira R, Novaes JF, Azeredo LM et al. (2013) Association of vitamin D insufficiency with adiposity and metabolic disorders in Brazilian adolescents. Public Health Nutr (Epublication ahead of print version).

31. Alemzadeh R, Kichler J, Babar G et al. (2008) Hypovitaminosis D in obese children and adolescents: relationship with adiposity, insulin sensitivity, ethnicity, and season. Metabolism 57, 183-191.

32. Cheng S, Massaro JM, Fox CS et al. (2010) Adiposity, cardiometabolic risk, and vitamin D status: the Framingham Heart Study. Diabetes 59, 242-248.

33. Harel Z, Flanagan P, Forcier M et al. (2011) Low vitamin D status among obese adolescents: prevalence and response to treatment. J Adolesc Health 48, 448-452.

34. Wortsman J, Matsuoka LY, Chen TC et al. (2000) Decreased bioavailability of vitamin D in obesity. Am J Clin Nutr $\mathbf{7 2}$, 690-693.

35. Harris SS \& Dawson-Hughes B (2007) Reduced sun exposure does not explain the inverse association of 25-hydroxyvitamin D with percent body fat in older adults. J Clin Endocrinol Metab 92, 3155-3157.

36. Jungert A, Roth HJ \& Neuhauser-Berthold M (2012) Serum 25-hydroxyvitamin $\mathrm{D}_{3}$ and body composition in an elderly cohort from Germany: a cross-sectional study. Nutr Metab (Lond) 9, 42.

37. Chacko SA, Song Y, Manson JAE et al. (2011) Serum 25-hydroxyvitamin D concentrations in relation to cardiometabolic risk factors and metabolic syndrome in postmenopausal women. Am J Clin Nutr 94, 209-217.

38. Foo L, Zhang Q, Zhu K et al. (2009) Relationship between vitamin $\mathrm{D}$ status, body composition and physical exercise of adolescent girls in Beijing. Osteoporosis Int 20, 417-425.

39. Valtuena J, Gonzalez-Gross M, Huybrechts I et al. (2013) Factors associated with vitamin D deficiency in European adolescents: the HELENA study. J Nutr Sci Vitaminol 59, 161-171.

40. Hirani V \& Primatesta P (2005) Vitamin D concentrations among people aged 65 years and over living in private households and institutions in England: population survey. Age Ageing 34, 485-491.

41. Valtueña J, Gracia-Marco L, Huybrechts I et al. (2013) Cardiorespiratory fitness in males, and upper limbs muscular strength in females, are positively related with 25-hydroxyvitamin D plasma concentrations in European adolescents: the HELENA study. QJ Med 106, 809-821.

42. DiVasta AD, Feldman HA, Brown JN et al. (2011) Bioavailability of vitamin $\mathrm{D}$ in malnourished adolescents with anorexia nervosa. J Clin Endocrinol Metab 96, 2575-2580.

43. Bjørge T, Engeland A, Tverdal A et al. (2008) Body mass index in adolescence in relation to cause-specific mortality: a follow-up of 230,000 Norwegian adolescents. Am J Epidemiol 168, 30-37.

44. De Wit LM, Van Straten A, Van Herten M et al. (2009) Depression and body mass index, a U-shaped association. BMC Public Health 9, 14.

45. Baumgartner RN, Heymsfield SB \& Roche AF (2012) Human body composition and the epidemiology of chronic disease. Obes Res 3, 73-95.

46. Bozzetto S, Carraro S, Giordano G et al. (2011) Asthma, allergy and respiratory infections: the vitamin $\mathrm{D}$ hypothesis. Allergy 67, 10-17. 